\title{
Cyclic Pressure Variations in A Small Diesel Engine Fueled with Biodiesel and Antioxidant Blend
}

\author{
Mohd Hafiz Ali ${ }^{1}$, Abdullah Adam²*, Mohd Hafizil Mat Yasin ${ }^{1}$ and Mohd Kamal Kamarulzaman² \\ ${ }^{1}$ Department of Petrochemical Engineering, Politeknik Tun Syed Nasir Syed Ismail, 84600 Pagoh, Johor, Malaysia \\ Phone: +60197546939; \\ ${ }^{2}$ Faculty of Mechanical Engineering, Universiti Malaysia Pahang 26600 Pekan Pahang, Malaysia
}

\begin{abstract}
Biodiesel fuel is considered as one of the most competence sustainable replacement for fossil fuel due to their superior combustion characteristics and possesses higher oxygen content. Thus, many researchers recently investigated to improve biodiesel capability by adding additives whether by blending with dual-fuel or tri-fuel. However, the combustion characteristics for biodiesel and biodiesel-additives blends are not thoroughly examined and need additional research works to study how the biodiesel behaviour and characterise. Thus, this research main objective is to study a single-cylinder diesel engine cyclic cylinder pressure variations running with biodiesel with antioxidant (B2HA1.0 and B2HT1.0) blends with palm oil methyl ester (POME). While The baseline fuels used for this study were biodiesel (B20) and pure diesel (B0). The entire test fuels were examined at a constant engine speed $1800 \mathrm{rpm}$ with $100 \%$ engine load condition. The engine combustion characteristics were studied by utilising the indicated mean effective pressure (IMEP) and cyclic variations of combustion pressure at 200 consecutive cycles. Combustion characteristics of engine diesel have been studied by using statistical analysis. The results revealed that the engine running with biodiesel-antioxidants have higher cyclic variations of combustion from $\mathrm{B} 20$ and $\mathrm{B} 0$, which $\mathrm{B} 2 \mathrm{HA} 1.0$ possessed the highest cyclic variations. It can be summarised from the study that biodiesel-antioxidants fuels produce a substantial influence on the engine cyclical variation, which linked to the characteristics of the engine combustion.
\end{abstract}

\author{
ARTICLE HISTORY \\ Revised: 1 st Apr 2020
}

Accepted: $25^{\text {th }}$ May 2020

\section{KEYWORDS}

Cyclic pressure variations;

Diesel engine;

Antioxidant; Palm oil

methyl ester (POME)

\section{INTRODUCTION}

Biodiesel has been discovered as one of the reliable replacements for mineral fuels, which comparable to pure diesel in term of combustion characteristics. Various literary works have studied and defined the abilities of the biodiesel involving the effects on engine performances, their properties, combustion characteristic and emissions [1-4]. Biodiesel fuels have numerous advantages comprising of higher oxygen content, higher Cetane Number $(\mathrm{CN})$ with lower sulfur which leads to reduce harmful emission during combustion [5-9]. However, biodiesel fuel produced higher $\mathrm{NO}_{\mathrm{x}}$ emission due to better combustion with the availability of oxygen in the biodiesel fuel [10-12]. One of the conventional methods to reduce $\mathrm{NO}_{\mathrm{x}}$ emission from biodiesel combustion is by addition of antioxidants as phenolic hydroxyl groups in the antioxidants inhibit with the prompt of $\mathrm{NO}_{\mathrm{x}}$ mechanism [13]. Another advantage of adding antioxidant into biodiesel led to producing a slightly higher power with lower calorific value with a similar quantity of fuel consumption [14]. The internal combustion engine characteristics are influenced by numerous parameters that exaggerated the combustion properties such as rate of heat release, in-cylinder pressure and temperature which lead to changes in engine power. The previous study has revealed that the diffusion in the portion of the burning rate and combustion existed from the start of combustion and the cyclic variations occurred [15]. Thus, the investigation on cyclic variations of a diesel engine is vital to know the performance of the engine when an alternative fuel and new technologies are used. Nowadays, diesel engines experiment were done to examine the in cyclic variation because of different fuels are being tested with diesel engine such as biodiesel [5, 16-18]. This study aims to evaluate and measure a small diesel engine cyclic variations of in-cylinder pressure operated with pure diesel (B0), palm oil methyl ester $20 \%+$ pure diesel $80 \%$ (B20) and biodiesel with antioxidants addition at $1000 \mathrm{ppm}$ (B2HA1.0 and B2HT1.0) blends. Effects on the diesel engine with a constant engine speed of $1800 \mathrm{rpm}$ at $100 \%$ engine loads with 200 consecutive cycles on IMEP and cyclic variations of the in-cylinder pressure as well as COVIMEP for are evaluated and elaborated comprehensively. 


\section{METHODOLOGY}

\section{Cyclic variation analysis}

Coefficient of variance $(\mathrm{COV})$ is determined as the ratio between the standard deviation $(\sigma)$ in the indicated mean effective pressure (IMEP) over consecutive cycles divided by its mean value [19]:

$$
\mathrm{COV}_{\text {IMEP }}=\frac{\sigma_{\text {IMEP }}}{\overline{\mathrm{IMEP}}} \times 100 \%
$$

where $\overline{I M E P}$ is the mean value of the IMEP and $\sigma$ IMEP is the standard deviation of the IMEP

$$
\sigma \mathrm{IMEP}=\sqrt{\frac{1}{\mathrm{~N}}} \sum_{\mathrm{i}=1}^{\mathrm{N}}\left(\text { IMEP }_{\mathrm{i}}-\overline{\mathrm{IMEP}}^{2}\right.
$$

The mean value of IMEP is given by:

$$
\overline{\operatorname{IMEP}}=\frac{1}{\mathrm{~N}} \sum_{\mathrm{i}=1}^{\mathrm{N}} \mathrm{IMEP}_{\mathrm{i}}
$$

where IMEP $_{\mathrm{i}}$ is indicated mean effective pressure in individual cycles and $\mathrm{N}$ is the number of cycles. The variation of degree among two-time series even their mean values are different from each other was evaluated using the coefficient of variation (COV) [20].

\section{Error Analysis}

An uncertainty analysis or errors of an experimental is required to reveal the accuracy of the experiments. The analysis will be converted as uncertainties and error through the instruments utilized in data collections recorded from the test can affect the result [21]. The experimental uncertainty can be affected by various reasons such as the type of the instrument devices, measurement methods selected, surrounding conditions, and the arrangement of the experimental setup. An uncertainty analysis is required to verify the exactness of the experiment. The instrument's uncertainties for the calculate parameters such as Brake thermal efficiency (BTE) and Brake specific fuel consumption (BSFC) were obtained using propagation of the uncertainties of the relevant, computable parameters in Eq. (2).

Propagation of general uncertainty formula:

If,

$$
\begin{gathered}
y=x_{1} \times x_{2} \times x_{3} \ldots . x_{n} \\
{[\Delta y]^{2}=\sum_{i=1}^{n}\left[\frac{\delta y}{\delta x i} \times \Delta x\right]^{2}}
\end{gathered}
$$

where: $\mathrm{y}=$ parameter, $\Delta \mathrm{y}=$ uncertainty of parameter, $\mathrm{x}_{1} \times \mathrm{x}_{2} \times \mathrm{x}_{3} \ldots \mathrm{x}_{\mathrm{n}}=$ variables of $\mathrm{y}$ and $\Delta x_{1}, \Delta x_{2}, \Delta x_{3}, \ldots \Delta x=$ accuracy or uncertainty of variables. The uncertainty of a certain operational condition is defined using Eq. (2). The calculated uncertainties from the experiment are BSFC: $\pm 1 \%, \mathrm{BTE}: \pm 1 \%$. The instruments measurement range and accuracy are shown in Table 1.

Table 1. Instruments measurement range and accuracy.

\begin{tabular}{lcccc}
\hline Instruments & Parameter & Sensor type & Range & Accuracy \\
\hline Speed sensor & Engine speed & Proximity sensor & $0-15,000 \mathrm{rpm}$ & \pm 1 \\
Load sensor & Brake torque & S type & $0-500 \mathrm{~kg}$ & \pm 0.1 \\
Pressure pickup & Cylinder pressure & Piezo type & $0-3,000 \mathrm{psi}$ & \pm 0.1 \\
Crank angle encoder & Crank position & Proximity sensor & $0-360{ }^{\circ} \mathrm{CA}$ & \pm 0.1 \\
\hline
\end{tabular}

\section{Engine Test}

In this experimental work, pure diesel, palm oil methyl ester (POME) biodiesel and antioxidant additives butylated hydroxyanisole (BHA) and butylated hydroxytoluene (BHT) were bought from a local supplier company. The fuels were mixed at $20 \%$ by volume of POME which is designated as B20 (80\% mineral diesel $+20 \%$ POME). While the antioxidant additives were blended at $1000 \mathrm{ppm}$ for each antioxidant with $1 \mathrm{~kg}$ of B20 designated as B2HA1.0 and B2HT1.0, respectively. ASTM standards were used to verify the thermal physical properties of the fuel blends such as viscosity, density and calorific value. In this study, fuel samples density was measured at $15{ }^{\circ} \mathrm{C}$ using a KEM Portable Density Meter (model DA-130N), whereas a digital constant temperature kinematic viscosity bath (model K23376 KV1000) at a temperature of $40 \pm 0.1{ }^{\circ} \mathrm{C}$ was used to test the viscosity for each fuel. Consequently, the determination of fuel 
heating/calorific value is by using an Oxygen Bomb Calorimeter, model 6772 (Parr instrument company, USA). A UP400S Ultrasonic processor at 5 minutes with $500 \mathrm{ml}$ each running time was utilized to perform the blending process. All the test fuel properties used in the experiment are listed in Table 2. This study used a Yanmar TF120-M small diesel engine with $7.8 \mathrm{~kW}$ at $2400 \mathrm{rpm}$ of maximum output power. Therefore, a controller model DC5 was used to adjust the torque and engine speed from a $15 \mathrm{~kW}$ eddy current dynamometer that was attached to the test engine. A fuel valve system was used with two individual fuel tanks with thermocouples, one for diesel fuel and one for the blends. A weight scale model CAS TCS- 6 was used to measure the weight of each test fuels and recorded against time to each test fuels to measure the fuel intake. Figure 1 depicted the engine testing setup and Table 3 indicates the specification of the test engine. Table 4 shows the test condition for this experiment.

Table 2. Test fuel properties.

\begin{tabular}{lllll}
\hline Properties & B0 & B20 & B2HA1.0 & B2HT1.0 \\
\hline Density $\left(\mathrm{kg} / \mathrm{m}^{3}\right)$ & 826 & 843 & 845 & 845 \\
Viscosity $(\mathrm{mPa} \cdot \mathrm{s})$ & 3.60 & 4.05 & 4.06 & 4.06 \\
Calorific value $(\mathrm{MJ} / \mathrm{Kg})$ & 45.89 & 45.01 & 44.88 & 44.91 \\
\hline
\end{tabular}

Table 3. Specification of test engine.

\begin{tabular}{lc}
\hline & Specification \\
\hline Engine type & YANMAR TF120M \\
Number of cylinders & 1 \\
Bore x stroke & $92 \times 96 \mathrm{~mm}$ \\
Displacement & $0.638 \mathrm{~L}$ \\
Compression ratio & 17.7 \\
Injection timing & $17^{\circ}$ BTDC \\
Continuous output & $10.5 \mathrm{HP}$ at $2400 \mathrm{rpm}$ \\
Rated output & $12 \mathrm{HP}$ at $2400 \mathrm{rpm}$ \\
Cooling system & Water cooled \\
\hline
\end{tabular}

Table 4. Test condition.

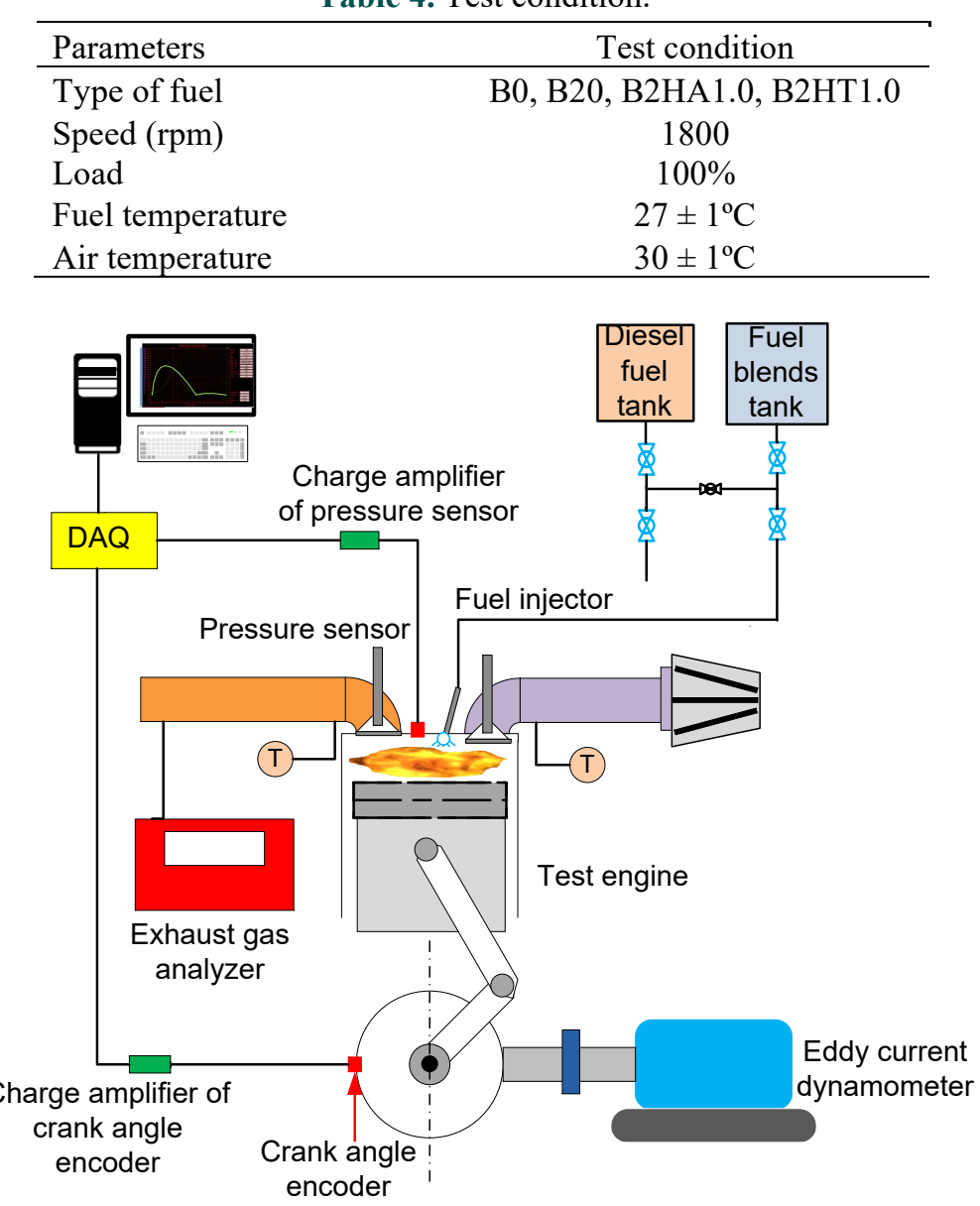

Figure 1. Engine testing set-up. 
An Optrand AutoPSI-S model C82294-Q pressure transducer was used to measure and log the cylinder pressure with $1.55 \mathrm{mV} / \mathrm{psi}$ and measurement range from 0-5000 psi due to the experiment focuses on the deviations of cyclic engine variation on the peak by peak cylinder changes. A magnetic crank encoder was attached to acquire the signal of the crank angle degree. These crank angle and in-cylinder pressure signal measurement were logged and examined with a TFX combustion analyzer as shown in Table 3 with specific test condition Whereas, 200 consecutive cycles in-cylinder pressure data were set and recorded to be analysed. In this experimental work, the coefficient of variation of the IMEP (COVIMEP) was utilized to evaluate the cyclic variations of the IMEP time series.

\section{RESULT AND DISCUSSION}

The effects the engine running with the test fuels at $100 \%$ engine load with a constant speed of 1800 rpm referring to cyclic pressure variations are discussed in this section. The assessment of the engine cyclic pressure variations of test fuels as the foundation for comparison to assess the other test fuels is further elaborated.
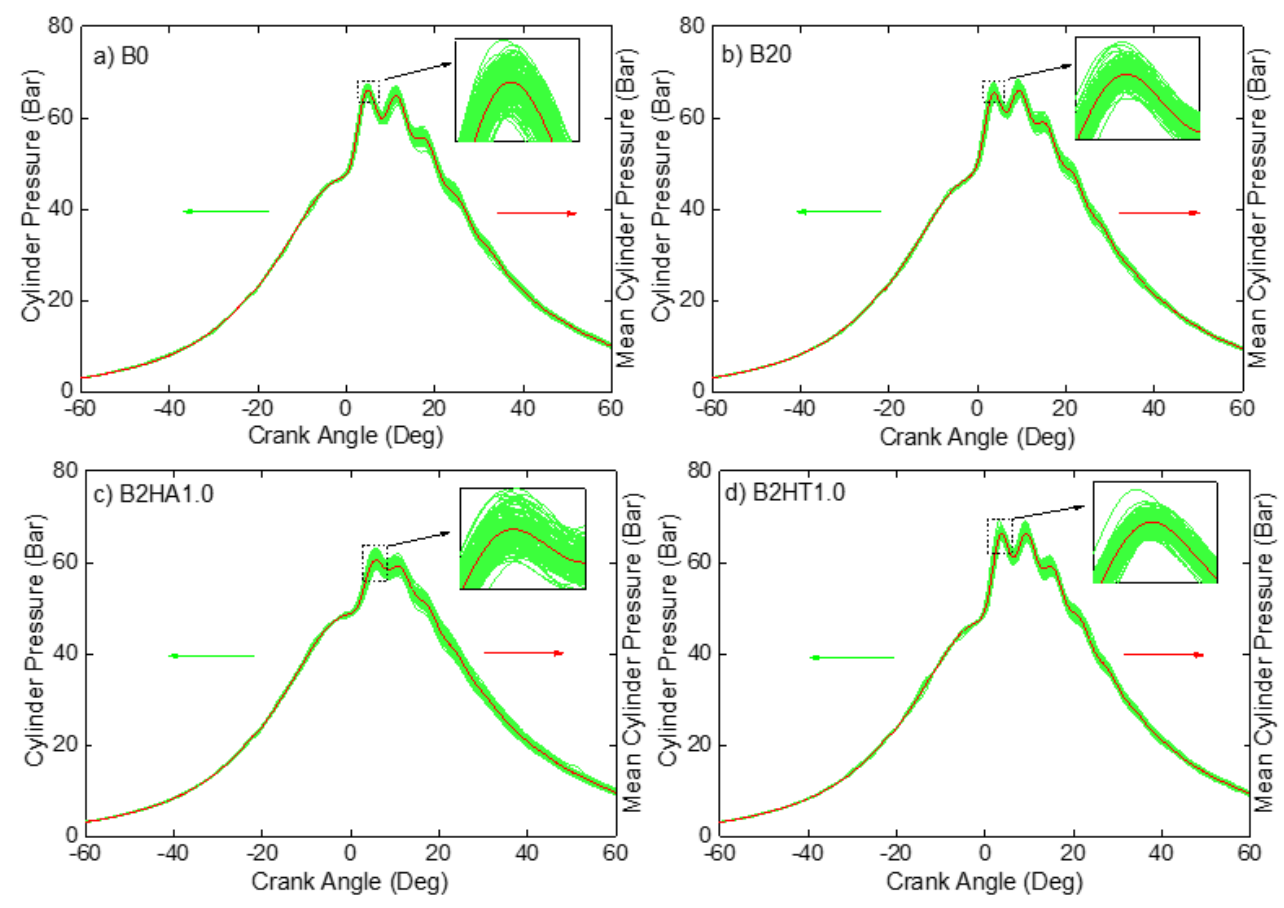

Figure 2. In-cylinder pressure variations and mean cylinder pressure with $100 \%$ engine load at $1800 \mathrm{rpm}$.

Figure 2 plotted a mean cylinder pressure and 200 consecutive cylinder pressure curves against the crank angle degree with constant engine speed at $1800 \mathrm{rpm}$ with $100 \%$ engine load was used for all the test fuels. From Figure 2, it depicted that the engine produced more cyclic variations when running with B20, B2HA1.0 and B2HT1.0 compare to B0. Referring to Figure 2(c), B2HA1.0 has greater variations of cylinder pressure curves produced from the engine. Whereas, the mean cylinder pressure results showed that B0 has the highest mean cylinder pressure at 71.2 bar when compared to B20 at 67.7 bar, followed by B2HA1.0 and B2HT1.0 at 62.1 and 68.5 bar, respectively. It can be concluded that with the addition of antioxidant of BHA and BHT, lower cylinder pressure was attained in biodiesel-antioxidant blends. Referring to Figure 2, the antioxidant blended fuels have lower peak occurred. The reason is due to their higher $\mathrm{CN}$ that is resulting in shorter ignition delay as agreed by Kivevele \& Huan [22] and Rashedul et al.[23].

The indicated mean effective pressure (IMEP) describes a specific combustion cycle [24]. Thus, the IMEP time series data were collected for 200 consecutive cycles of the cylinder pressure data at specific engine test condition (1800 rpm engine speed with full engine load). It can be observed that B0 and B20 produced a greater IMEP compared to other test fuels at 100\% engine load as shown in Figure 3. Furthermore, Figure 3 also reveals that B0 is the most stable fuel during combustion as the IMEP distribution concentrate near the mean IMEP line for 200 consecutive cycles. The highest average IMEP logged is B0 at 7.1 bar while B20 at 6.6 bar, followed by B2HT1.0 and B2HA1.0 at 6.4 and 6.3 bar, respectively. Biodiesel-antioxidant blends tend to have lower IMEP from other test fuels (B0 and B20) due to the antioxidant additives ability that hindered the fuel transformation [25] and reduction of oxidative free radical formation [26], which led to producing less efficient combustion. 

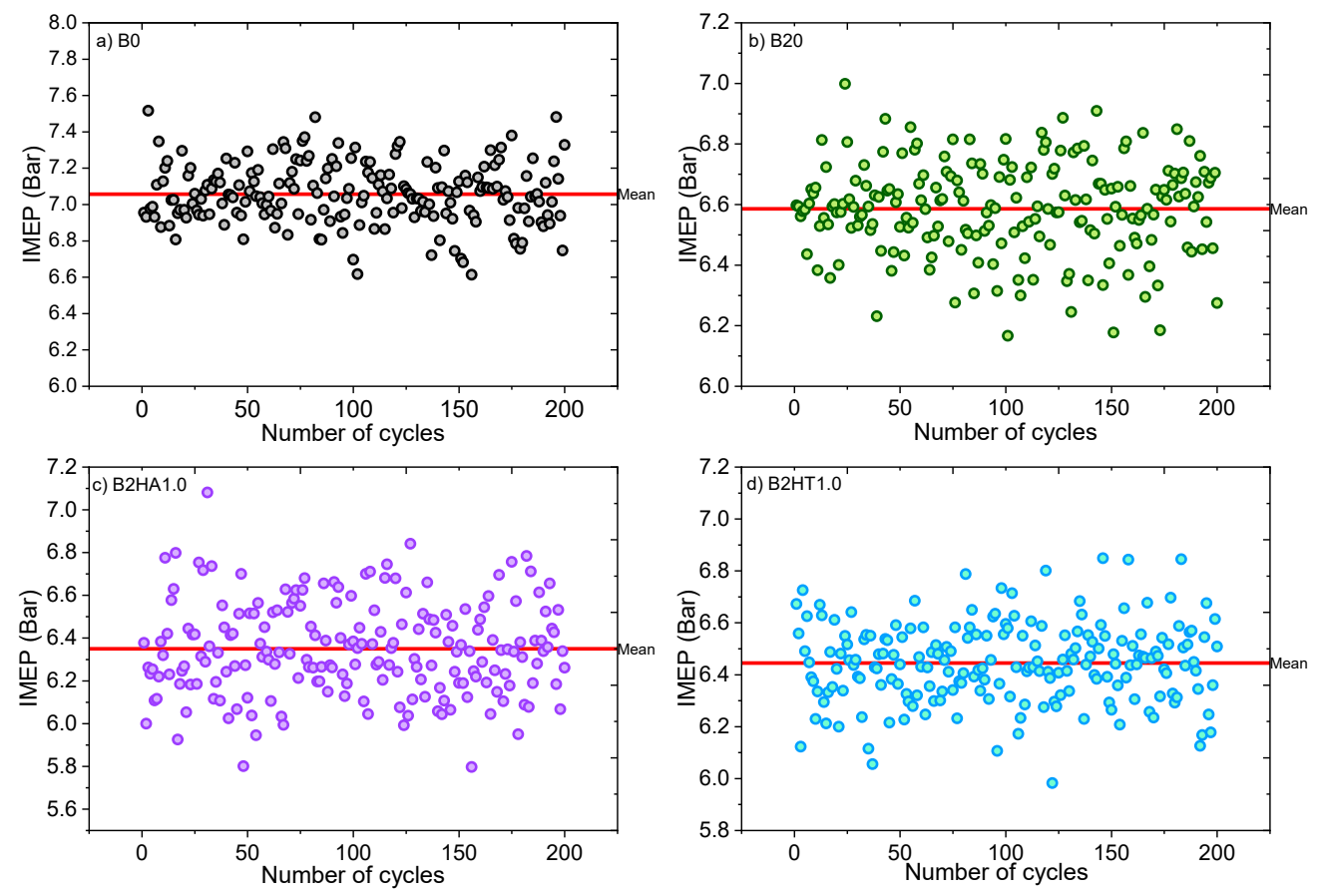

Figure 3. Variation of IMEP with 100\% engine load at $1800 \mathrm{rpm}$.

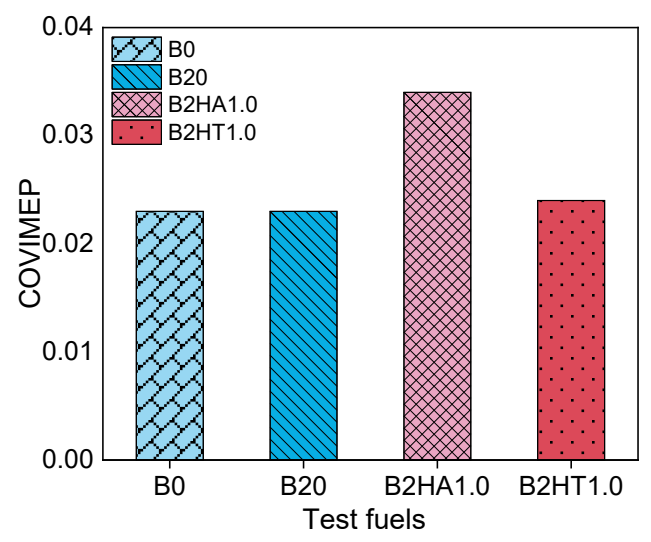

Figure 4. COVIMEP with $100 \%$ engine load at $1800 \mathrm{rpm}$ from 200 consecutive cycles.

Another essential measure of cyclic variability is the COV in IMEP. Figure 4 shows the non-repeatability of the value of indicated mean effective pressure (COVIMEP) for all test fuels. It can be observed that in the case of both antioxidants treated fuels, the existent of antioxidant content in the fuel leads to an increase in the COVIMEP coefficient, which results in reducing engine operation stability. This may occur from the antioxidant ability to inhibit the prompt of NOx formation and the oxidation of the oxygen content during combustion and make the combustion less efficient [23]. Thus, reducing the speed and intensification of the combustion process. B2HA1.0 fuel is observed has the highest COVIMEP at 0.034\%. This means that the combustion of biodiesel blends with antioxidant additions is very stable without large cycle-by-cycle variations. It can be concluded that all the test fuels were considered to have an even and stable operation, for which the COVIMEP was much lower than the acceptable limit for reciprocating combustion engine about $10 \%$ [27].

\section{CONCLUSION}

The properties of the test fuels including the biodiesel-antioxidant (BHA and BHT) blends cyclic variations in this research work were studied and assessed compared to the B0 and B20 as baseline fuels. COVIMEP was used to analyze the engine cyclic variations of the test fuels. The conclusions are as follows:

i. The outcomes from fuel properties examination display an increase in viscosity and density of biodiesel blends with BHA and BHT antioxidant.

ii. The COVIMEP was evaluated and designates that the IMEP for each test fuel produces the engine stability. The engine has poorer stability when having a higher COVIMEP value.

iii. It is discovered that the highest value of COVIMEP belongs to B2HA1.0 as compared to other test fuels. 


\section{ACKNOWLEDGEMENT}

The authors would like to recognise the involvement through the technical specialists in Malaysian Ministry of Higher Education, Engine Research Group and Universiti Malaysia Pahang is recognized under RAGS grant (RDU1603100) and Department of Polytechnic Education for the financial and technical support.

\section{REFERENCES}

[1] Othman MF, Abdullah AA, Kamal K, Asri S, Azmi Z, Mamat R. Improvement of fuel properties for palm oil methyl ester (POME) biodiesel blends using organic germanium as additives. IOP Conference Series: Materials Science and Engineering. 2019;469:012121.

[2] Othman MF, Adam A, Najafi G, Mamat R. Green fuel as alternative fuel for diesel engine: A review. Renewable and Sustainable Energy Reviews. 2017;80:694-709.

[3] Saravanan A, Murugan M, Sreenivasa Reddy M, Parida S. Performance and emission characteristics of variable compression ratio CI engine fueled with dual biodiesel blends of Rapeseed and Mahua. Fuel. 2020;263:116751.

[4] Simsek S. Effects of biodiesel obtained from Canola, sefflower oils and waste oils on the engine performance and exhaust emissions. Fuel. 2020;265:117026.

[5] Mat Yasin MH, Mamat R, Najafi G, Ali OM, Yusop AF, Ali MH. Potentials of palm oil as new feedstock oil for a global alternative fuel: A review. Renewable and Sustainable Energy Reviews. 2017;79:1034-49.

[6] Adzmi MA, Abdullah A, Naqiuddin A. Combustion characteristics of biodiesel blended with $\mathrm{Al} 2 \mathrm{O} 3$ and $\mathrm{SiO} 2$ nanoparticles. AIP Conference Proceedings. 2019;2059:020052.

[7] Othman MF, Abdullah AA, Asri S, Azmi Z, Yasin MHM, Abdullah Z, et al. A comparative study on performance characteristics of diesel engine fuelled by biodiesel blends with and without Ge-132 additive. IOP Conference Series: Materials Science and Engineering. 2019;469:012122.

[8] Goga G, Chauhan BS, Mahla SK, Cho HM. Performance and emission characteristics of diesel engine fueled with rice bran biodiesel and n-butanol. Energy Reports. 2019;5:78-83.

[9] Rajak U, Nashine P, Verma TN. Effect of spirulina microalgae biodiesel enriched with diesel fuel on performance and emission characteristics of CI engine. Fuel. 2020;268:117305.

[10] Chen H, Xie B, Ma J, Chen Y. NOx emission of biodiesel compared to diesel: Higher or lower? Applied Thermal Engineering. 2018;137:584-93.

[11] Ndayishimiye P, Tazerout M. Use of palm oil-based biofuel in the internal combustion engines: Performance and emissions characteristics. Energy. 2011;36:1790-6.

[12] Ali MH, Abdullah A, Yasin MHM. Effect of BHA and BHT antioxidant additives on engine performance and emission of a CI engine fueled with a palm oil methyl ester- diesel fuel blend AIP Conference Proceedings. 2019;2059,020051.

[13] Rizwanul Fattah IM, Masjuki HH, Kalam Ma, Mofijur M, Abedin MJ. Effect of antioxidant on the performance and emission characteristics of a diesel engine fueled with palm biodiesel blends. Energy Conversion and Management. 2014;79:265-72.

[14] Ryu K. The characteristics of performance and exhaust emissions of a diesel engine using a biodiesel with antioxidants. Bioresource Technology. 2010;101:S78-S82.

[15] Maurya RK, Saxena MR, Akhil N. Experimental Investigation of Cyclic Variation in a Diesel Engine Using Wavelets. Intelligent Systems Technologies and Applications Advances in Intelligent Systems and Computing, Springer. 2016;384:247-57.

[16] Ali OM, Mamat R, Abdullah NR, Abdullah AA. Analysis of blended fuel properties and engine performance with palm biodiesel-diesel blended fuel. Renewable Energy. 2016;86:59-67.

[17] Mat Yasin MH, Mamat R, Yusop AF, Abdullah AA, Othman MF, Yusrizal ST, et al. Cylinder Pressure Cyclic Variations in a Diesel Engine operating with Biodiesel-Alcohol Blends. Energy Procedia. 2017;142:303-8.

[18] Turkcan A. The effects of different types of biodiesels and biodiesel-bioethanol-diesel blends on the cyclic variations and correlation coefficient. Fuel. 2020;261:116453.

[19] Zhang HG, Han XJ, Yao BF, Li GX. Study on the effect of engine operation parameters on cyclic combustion variations and correlation coefficient between the pressure-related parameters of a CNG engine. Applied Energy. 2013;104:992-1002.

[20] Sen AK, Ash SK, Huang B, Huang Z. Effect of exhaust gas recirculation on the cycle-to-cycle variations in a natural gas spark ignition engine. Applied Thermal Engineering. 2011;31:2247-53.

[21] Senturk Acar M, Arslan O. Exergo-economic Evaluation of a new drying system Boosted by Ranque-Hilsch vortex tube. Applied Thermal Engineering. 2017;124:1-16.

[22] Kivevele T, Huan Z. Effects of Antioxidants on the Cetane number, Viscosity, Oxidation Stability, and Thermal Properties of Biodiesel Produced from Nonedible Oils2013.

[23] Rashedul HK, Masjuki HH, Kalam MA, Teoh YH, How HG, Fattah IMR. Effect of antioxidant on the oxidation stability and combustion - performance - emission characteristics of a diesel engine fueled with diesel biodiesel blend. Energy Conversion and Management. 2015;106:849-58.

[24] Ali OM, Rosli N, Mamat R, Adam A. Comparison Of The Effect Of Different Alcohol Additives With Blended Fuel On Cyclic Variation In Diesel Engine. Energy Procedia. 2015;75:2357-62. 
[25] Prabu SS, Asokan MA, Roy R, Francis S, Sreelekh MK. Performance, combustion and emission characteristics of diesel engine fuelled with waste cooking oil bio-diesel / diesel blends with additives. Energy. 2017;122:63848.

[26] Varatharajan K, Cheralathan M, Velraj R. Mitigation of NOx emissions from a jatropha biodiesel fuelled di diesel engine using antioxidant additives. Fuel. 2011;90:2721-5.

[27] Heywood JB. Internal combustion engine fundamentals. New York: Mcgraw-Hill; 1988. 